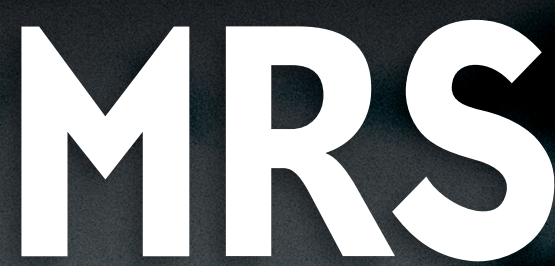

$M|R| S$
MATERIALS RESEARCH SOCIETY®

Advancing materials. Improving the quality of life.

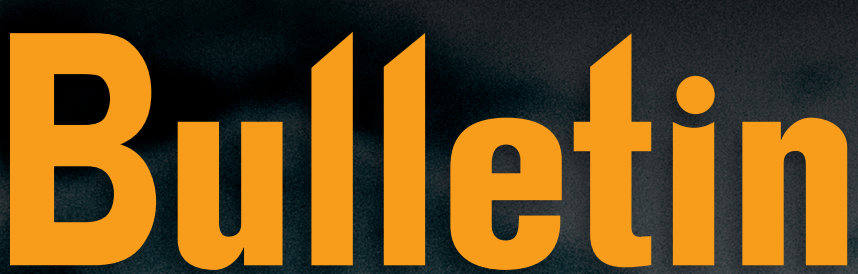

October 2020 Vol. 45 No. 10 mrs.org/bulletin

\title{
Functional materials and devices by self-assembly
}

\section{ALSO LI THS ISSUE}

\section{Double-transition-metal MXenes:}

Atomistic design of 2D carbides

and nitrides

- 


\section{CUSTOMIZED PRODUCTION ION IMPLANTERS}

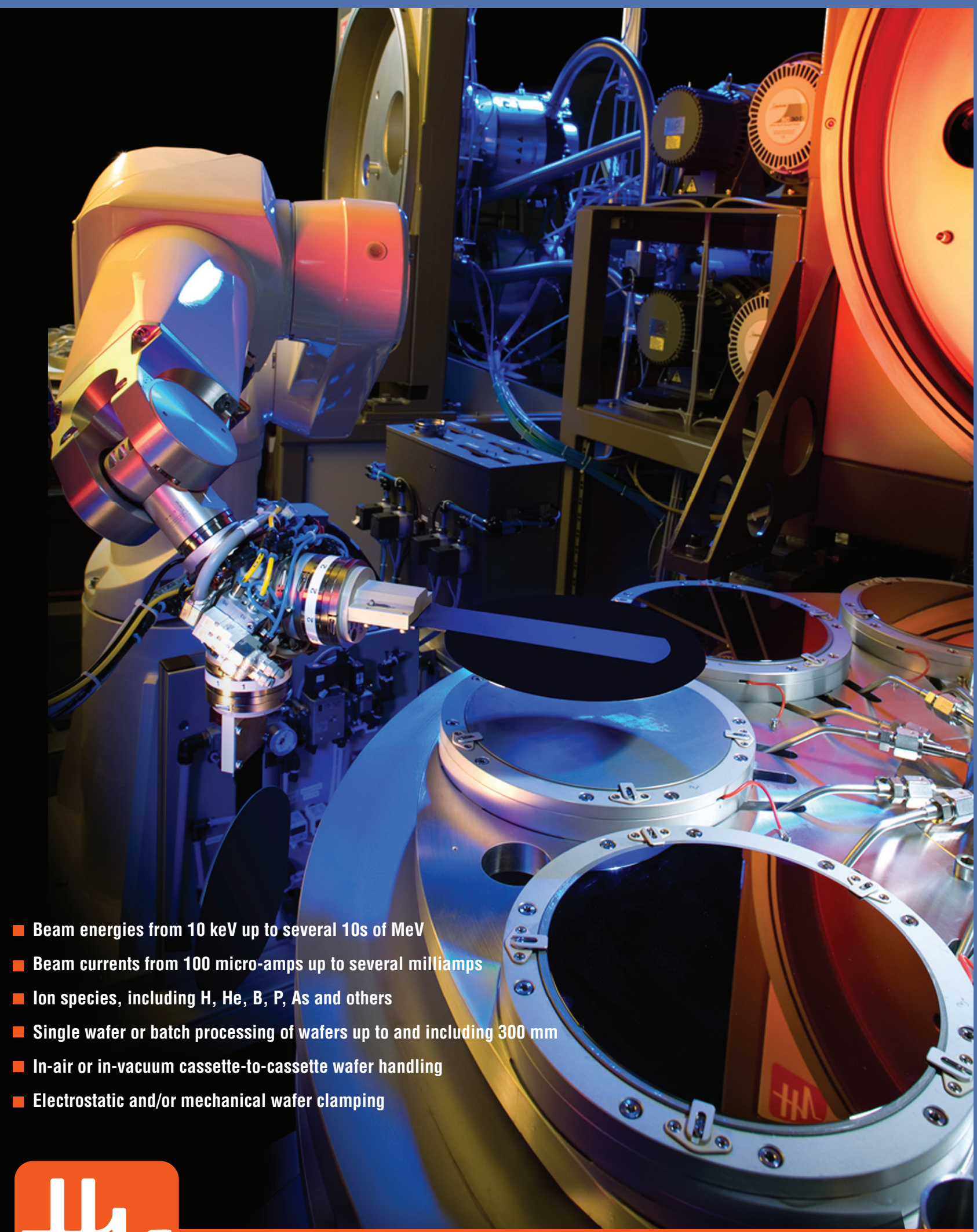

In-air or in-vacuum cassette-to-cassette wafer handling

Electrostatic and/or mechanical wafer clamping

\section{High Voltage Engineering}

High Voltage Engineering Europa B.V.

P.O. Box 99, 3800 AB Amersfoort, The Netherlands

Tel: 31334619741 • info@highvolteng.com

www.highvolteng.com 


\section{Introducing:}
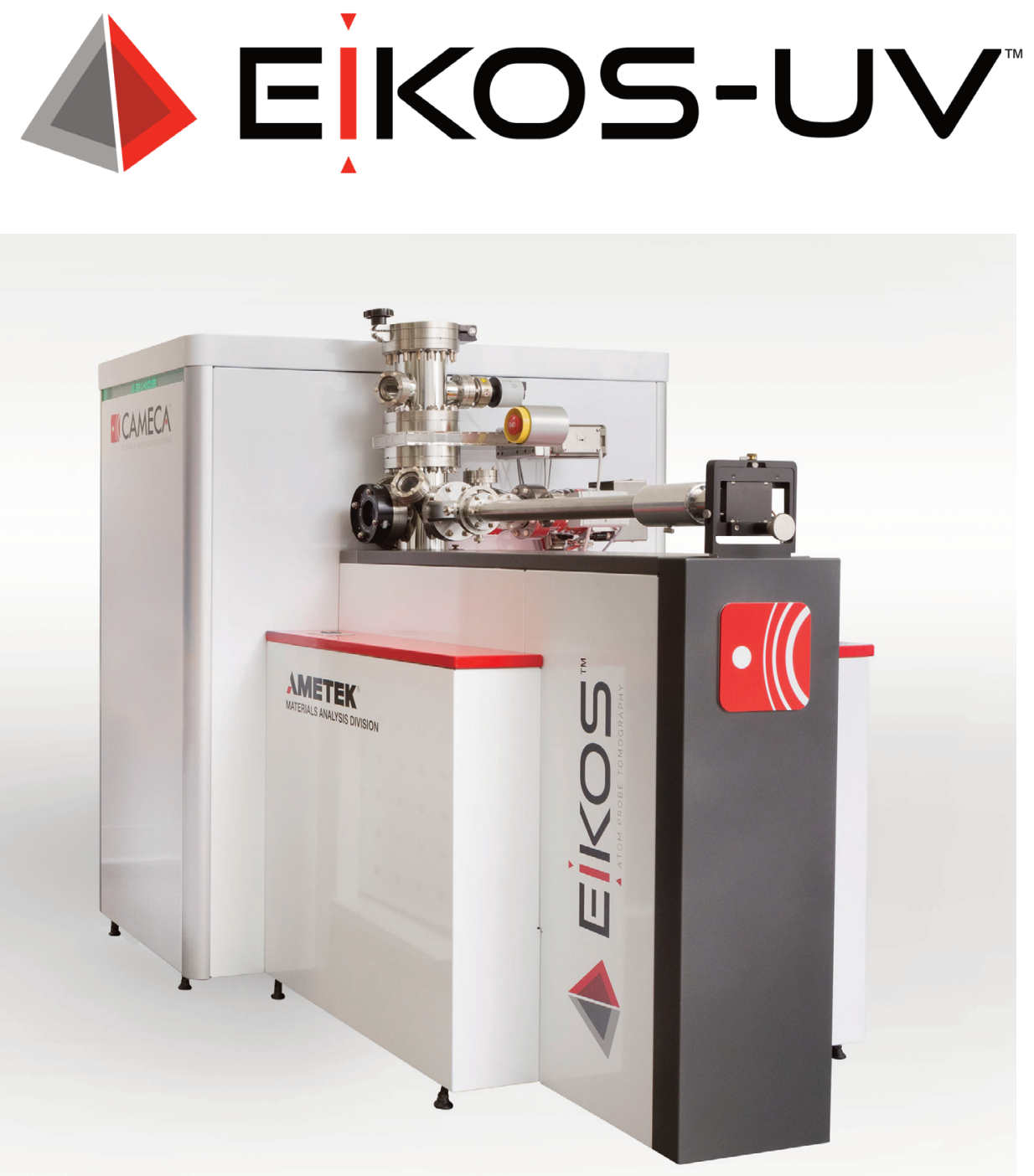

The Workhorse Atom Probe for Research \& Industry

CAMECA announces EIKOS-UVTM, the new Atom Probe microscope that brings APT to the next generation of scientists, metallurgists, physicists, geologists, and engineers.

EIKOS-UVTM - optimized for efficiency and simplicity delivers all the benefits of Atom Probe Tomography: three-dimensional nanoscale characterization of materials with the best combination of high spatial resolution and detection sensitivity in an easy to use, affordable instrument.

A new atom probe for academic and commercial environments addressing a wide range of applications: Metals - Coatings - Thin Films - Ceramics • Minerals - Functional Materials

CAMECA's range of APT instrumentation, including the LEAP ${ }^{\circledR} 5000$, EIKOS $^{T M}$, and EIKOS-UV ${ }^{T M}$, are driving research and production breakthroughs around the world. Learn how Atom Probe instruments can place your organization's research or processes at the forefront of your field. Contact CAMECA today.

Download our free APT introductory guide at:
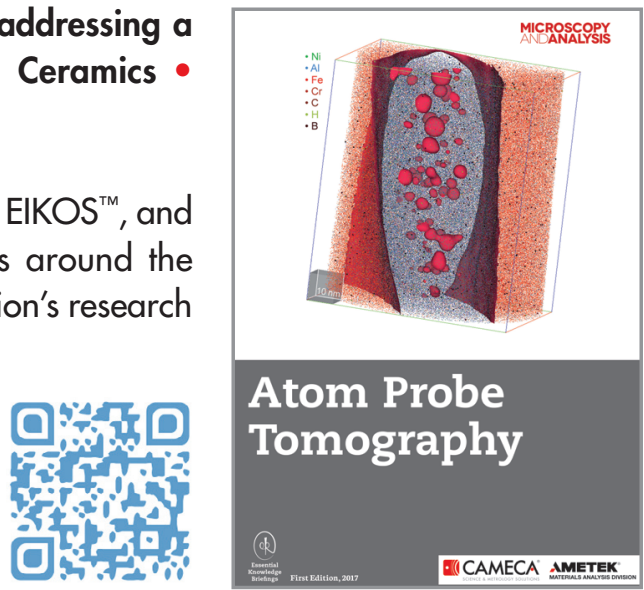

Full product information and contacts at: www.cameca.com 


\section{MRSBulletin}

OCTOBER 2020 VOLUME 45 Number 10 ISSN: 0883-7694 CODEN: MRSBEA
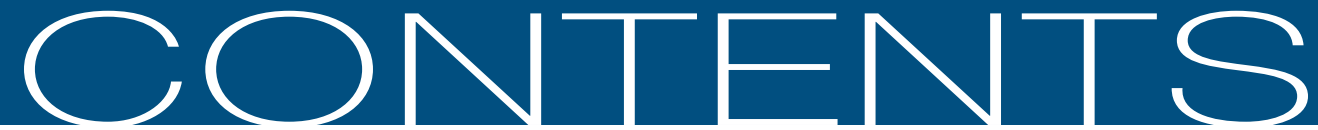

\section{FUNCTIONAL MATERIALS AND DEVICES BY SELF-ASSEMBLY}

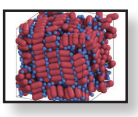

799 Functional materials and devices by self-assembly

Dmitri V. Talapin, ${ }^{*}$ Michael Engel, and Paul V. Braun, ${ }^{\star}$ Guest Editors*

807 Self-assembly for electronics

Cherie R. Kagan, Taeghwan Hyeon, Dae-Hyeong Kim, Ricardo Ruiz, Maryann C. Tung, and H.-S. Philip Wong

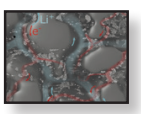

815 Self-assembled materials for electrochemical energy storage

Hao Chen, Peter Benedek, Khande-Jaé Fisher,

Vanessa Wood, and Yi Cui

823 Separation using self-assembled materials Fan Chen, Gregory S. Day, and Hong-Cai Zhou

832 Self-assembly of bioinspired and biologically functional materials

E. Thomas Pashuck, Ned Seeman, and Robert Macfarlane

841 Superradiant emission from self-assembled light emitters: From molecules to quantum dots

G. Rainò, H. Utzat, M.G. Bawendi, and M.V. Kovalenko

\section{TECHNICAL FEATURE}

850 Double transition-metal MXenes:

Atomistic design of two-dimensional

carbides and nitrides

Weichen Hong, Brian C. Wyatt,

Srinivasa Kartik Nemani, and Babak Anasori

\section{MRSBulletin}

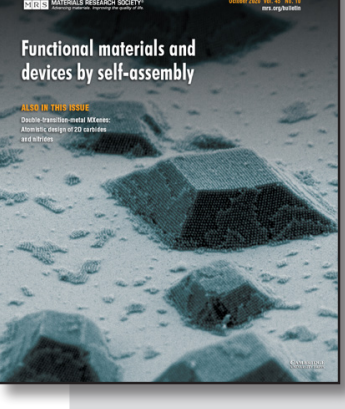

\section{ON THE COVER}

Functional materials and devices by selfassembly. Self-assembly allows for the development of new paradigms for chemistry and materials science, where various, typically nanometer-sized, objects with precisely engineered sizes, shapes, compositions, and concomitant properties serve as "meta-atoms" or superatomic building blocks for hierarchically assembled materials and devices. The current state of the field reveals that self-assembly is making significant strides toward applications in nanoelectronics, photonics, energy storage, chemical separations, and as a path to form complex structures. The cover shows singlecrystal nanoparticle superlattices assembled via DNA hybridization. The cover image relates to US Department of Navy Award No. N00014-19-1-2213 issued by the Office of Naval Research. The United States Government has a royaltyfree license throughout the world to the image. See the technical theme that begins on p. 799 .

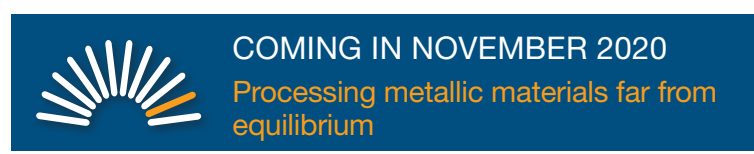




\section{DEPARTMENTS}

\section{OPINION}

789 Letter to the Editor Elton Kaufmann

\section{NEWS \& ANALYSIS}

\section{Materials News}

- Research Highlights: Perovskites Pabitra K. Nayak

- Nanoindentation on peeled high-performance polymeric fibers reveals failure mechanisms Hortense Le Ferrand

- Electrochemical energy-storage material architecture built brick-by-brick Boris Dyatkin

794 Science Policy

- COVID-19 pandemic highlights need for US policies that increase supply chain resilience Boris Dyatkin

- EC announces actions to increase security and sustainability of Europe's raw materials supply

\section{SOCIETY NEWS}

797 MRS Journal Highlights

863 MRS authors recently elected to the US National Academy of Engineering

\section{MRS Communications Abstracts}

\section{6eatures}

867 Book Reviews

- Graphene: Preparations, Properties, Applications, and Prospects

Kazuyuki Takai, Seiya Tsujimura, Feiyu Kang,

and Michio Inagaki

Reviewed by K.S.V. Santhanam

- Nanostructured Materials

T. Daniel Thangadurai, N. Manjubaashini, Sabu Thomas, and Hanna J. Maria

Reviewed by Mariana Amorim Fraga

- Nanoparticles Induce Oxidative and Endoplasmic Reticulum Stresses: Antioxidant Therapeutic Defenses Loutfy H. Madkour

Reviewed by Aurelia Meghea

872 Image Gallery

Look Again

\section{CAREER CENTRAL}

870 Career Feature

Creating meaningful slide presentations

Duanduan Han

871 Classified

\section{ADVERTISERS IN THIS ISSUE}

American Elements

Cameca

Electron Microscopy Sciences

High Voltage Engineering
Page No. .785 849 Inside front cover Outside back cover

\section{mrs.org/bulletin}

mrs.org/energy-quarterly

mrs.org/mymrs

journals.cambridge.org

mrs.org/bulletin-podcast

@mrsbulletin 


\section{$\mathrm{M}|\mathrm{R}| \mathrm{S}$}

MATERIALS RESEARCH SOCIETY ${ }^{\oplus}$

Advancing materials. Improving the quality of life.
EDITORIAL OFFICE 506 Keystone Drive, Warrendale, PA 15086-7573 USA

Bulletin@mrs.org tel 724.779.2747 fax 724.779.8313 mrs.org

\section{About the Materials Research Society}

The Materials Research Society (MRS), a not-for-profit scientific association founded in 1973 and headquartered in Warrendale, Pennsylvania, USA, promotes interdisciplinary materials research. Today, MRS is a growing, vibrant, member-driven organization of more than 14,000 materials researchers spanning over 80 countries, from academia, industry, and government, and a recognized leader in the advancement of interdisciplinary materials research.

The Society's interdisciplinary approach differs from that of single-discipline professional societies because it promotes information exchange across many scientific and technical fields touching materials development. MRS conducts three major international annual meetings and also sponsors numerous single-topic scientific meetings. The Society recognizes professional and technical excellence and fosters technical interaction through University Chapters. In the international arena, MRS implements bilateral projects with partner organizations to benefit the worldwide materials community. The Materials Research Society Foundation helps the Society advance its mission by supporting various projects and initiatives.

2020 MRS BOARD OF DIRECTORS

President Matt Copel, IBM T.J. Watson Research Center, USA

Immediate Past President Michael R. Fitzsimmons, Oak Ridge Nationa

Laboratory and The University of Tennessee, USA

Vice President (President-Elect) Cherie R. Kagan, University of Pennsylvania, USA

Secretary Dawnielle Farrar-Gaines, Johns Hopkins University, USA

Treasurer Shenda Baker, Synedgen Inc., USA

Executive Director Todd M. Osman, Materials Research Society, USA

Griselda Bonilla, IBM T.J. Watson Research Center, USA

Leonard J. Brillson, The Ohio State University, USA

Kristen H. Brosnan, GE Global Research, USA

Kristen H. Brosnan, GE Global Research, USA
Coray M. Colina, University of Florida, USA

Catherine Dubourdieu, Helmholtz-Zentrum Berlin/Freie Universität Berlin, Germany Sarah Heilshorn, Stanford University, USA

Frances A. Houle, Lawrence Berkeley National Laboratory, USA

Mônica Jung de Andrade, The University of Texas at Dallas, USA

Sergei V. Kalinin, Oak Ridge National Laboratory, USA

Kisuk Kang, Seoul National University, Republic of Korea

Paul C. McIntyre, Stanford University, USA

Linda S. Schadler, The University of Vermont, USA

Christopher A. Schuh, Massachusetts Institute of Technology, USA

Rachel A. Segalman, University of California, Santa Barbara, USA

Ting Xu, University of California, Berkeley, USA

Yusheng Zhao, Southern University of Science and Technology, China

Ehrenfried Zschech, Fraunhofer Institute for Ceramic Technologies and Systems, Germany

\section{MRS OPERATING COMMITTEE CHAIRS}

Academic Affairs Sanjay Mathur, University of Cologne, Germany

Awards (Co-chairs) Suveen N. Mathaudhu, University of California, Riverside, USA

Judith L. Driscoll, University of Cambridge, UK

Government Affairs David P. Norton, University of Florida, USA

Meetings Lincoln J. Lauhon, Northwestern University, USA

Public Outreach Elizabeth Kupp, The Pennsylvania State University, USA

Publications Shefford P. Baker, Cornell University, USA

\section{MRS HEADQUARTERS}

Todd M. Osman, Executive Director

J. Ardie Dillen, Director of Finance and Administration

Damon Dozier, Director of Government Affairs

Michele L. Feder, Associate Director of Engagement

Patricia Hastings, Director of Meetings Activities

Eileen M. Kiley, Director of Communications
Chief Editor for Technical Content

Gopal R. Rao, rao@mrs.org

Impact Editor

Markus J. Buehler

Theme Editor

Neville R. Moody

Managing Editor

Lori A. Wilson, Iwilson@mrs.org

News Editor

Judy Meiksin, meiksin@mrs.org

Technical Editor

Lisa C. Oldham, oldham@mrs.org

Editorial Assistants

Suzanne Hite, hite@mrs.org,

Mary Wilmoth

Director of Communications

Eileen M. Kiley
Guest Editors

Dmitri V. Talapin and Paul V. Braun

Special Consultants

Ken Haenen and Enrico Traversa

Production/Design

Stephanie Gabborin, Heather Shick,

Felicia Turano, and Tech-Set Ltd

Production Editor

Rachel Altizio

Advertising/Sponsorship

Mary E. Kaufold, kaufold@mrs.org

Donna L. Watterson, watterson@mrs.org

Member Subscriptions

Michelle Judt, judt@mrs.org

Non-Member Subscriptions

subscriptions_newyork@cambridge.org

\section{EDITORIAL BOARD}

Amit Misra (Chair), University of Michigan, USA

Ilke Arslan, Argonne National Laboratory, USA

N. (Balu) Balasubramanian, Bangalore, India (retired)

Christopher J. Bettinger, Carnegie Mellon University, USA

Tommie Kelley, 3M, USA

Igor Lubomirsky, Weizmann Institute, Israel

Fiona C. Meldrum, University of Leeds, UK

Steven C. Moss, The Aerospace Corporation, USA (retired)

Linda J. Olafsen, Baylor University, USA

Boaz Pokroy, Technion-Israel Institute of Technology, Israel

Zhiwei Shan, Xi'an Jiaotong University and Hysitron, China

Subhash L. Shinde, University of Notre Dame, USA

Eric Werwa, Washington, DC, USA

M. Stanley Whittingham, Binghamton University, The State University of New York, USA

IMPACT EDITORIAL BOARD

Katia Bertoldi, Harvard University, USA

Huiling Duan, Peking University, China

Peter FratzI, Max Planck Institute of Colloids and Interfaces, Germany

Pupa Gilbert, University of Wisconsin-Madison/Berkeley National Laboratory, USA

Ali Khademhosseini, University of California, Los Angeles, USA

John A. Rogers, Northwestern University, USA

Francesco Stellacci, École Polytechnique Fédérale de Lausanne, Switzerland

Kathryn E. Uhrich, University of California, Riverside, USA

ADVISORY BOARD

V.S. Arunachalam, Center for Study of Science, Technology and Policy, India

Paul Drzaic, Apple Inc., USA

Yury Gogotsi, Drexel University, USA

Robert S. Langer, Massachusetts Institute of Technology, USA

Ke Lu, Chinese Academy of Sciences, China

Rodney S. Ruoff, Institute for Basic Science, Center for Multidimensional Carbon Materials and UNIST, South Korea

Edwin L. (Ned) Thomas, Rice University, USA

Peidong Yang, University of California, Berkeley, USA

\section{VOLUME ORGANIZERS}

2020 Hongyou Fan, Sandia National Laboratories, USA Oleg Gang, Columbia University and Brookhaven National Laboratory, USA Seokwoo Jeon, Korea Advanced Institute of Science and Technology, Republic of Korea Tae-Woo Lee, Seoul National University, Republic of Korea

2021 Babu Chalamala, Sandia National Laboratories, USA Paul Evans, University of Wisconsin-Madison, USA Takao Someya, The University of Tokyo, Japan Haiyan Wang, Purdue University, USA

MRS Bulletin (ISSN: 0883-7694, print; ISSN 1938-1425, online) is published monthly by the Materials Research Society, 506 Keystone Drive, Warrendale, PA 15086-7573. @ 2020 Materials Research Society. Permission required to reproduce content. Periodical postage paid at New York, NY, and at additional mailing offices. POSTMASTER: Send address changes to MRS Bulletin in care of the Journals Department, Cambridge University Press, 100 Brook Hill Drive, West Nyack, NY 10994-2113, USA. Printed in the U.S.A.

Membership in MRS is $\$ 135$ annually for regular members, $\$ 35$ for students, and includes an electronic subscription to MRS Bulletin. Print subscriptions are available to MRS members for an additional \$25. Individual member subscriptions are for personal use only. Nonmember subscription rates are \$618 (USD) for one calendar year (12 issues). Requests from subscribers for missing journal issues will be honored without charge only if received within six months of the issue's actual date of publication.

MRS Bulletin is included in Current Contents ${ }^{\circledast} /$ Engineering, Computing, and Technology; Current Contents ${ }^{\circledast / P h y s i c a l, ~ C h e m i c a l, ~ a n d ~ E a r t h ~ S c i e n c e s, ~ t h e ~ S c i S e a r c h ~}{ }^{\circledast}$ online database, Research Alert ${ }^{\oplus}$, Science Citation Index ${ }^{\oplus}$, Materials Science Citation Index ${ }^{\top M}$, and Scopus.

Authors of each technical article appearing in MRS Bulletin are solely responsible for all content in their article(s), including accuracy of the facts, statements, and citing resources. Facts and opinions are solely the personal statements of the respective authors and do not necessarily represent the views of the editors, the Materials Research Society, or Cambridge University Press. 